\title{
LOS NEXOS DE SUBORDINACIÓN ORACIONAL: ANÁLISIS SOCIOLINGÜIISTICO
}

\author{
Rafael Jiménez Fernández
}

\begin{abstract}
In this work we analyse the frecuency in the use of subordinate clauses of the sevillian children's speech in relation with sociolinguistic variables such as sex and age.
\end{abstract}

En el presente estudio vamos a analizar la frecuencia de uso de los nexos subordinantes en el habla de los niños sevillanos ${ }^{1}$, teniendo en cuenta las variables sociolingüísticas de sexo y edad. A partir de las formas subordinantes oracionales registradas en la producción discursiva de este grupo de informantes hemos establecido el siguiente ordenamiento tipológico:
1. Que (conjunción)
9. Si
2. Relativos
10. Prep. + infinitivo
3. Interrogativos
11. Hasta/desde que
4. Donde
12. Como/por si
5. Cuando
13. Aunque
6. Como
14. Mientras/mientras que
7. Para que
15. Antes/después de que/inf.
8. Porque
16. Otros

Según el número de ocurrencias que presenta cada uno de estos elementos nexuales, presentamos esta primera distribución jerárquica en función de los resultados globales obtenidos:

$\begin{array}{lll}\text { Relativos } & 3.249 & 31,46 \% \\ \text { Que } & 2.604 & 25,23 \% \\ \text { Porque } & 1.188 & 11,50 \% \\ \text { Prep. + infinitivo } & 720 & 6,98 \% \\ \text { Si } & 631 & 6,10 \%\end{array}$

\footnotetext{
${ }^{1}$ Hemos tomado como corpus para este trabajo las producciones orales de 300 niños sevillanos -cuyas edades están comprendidas entre los 11 y 13 años- elegidos aleatoriamente de colegios ubicados en distintas zonas de la ciudad. Hemos tenido en cuenta asimismo las variables de edad y sexo. Estos informantes, 150 varones y 150 hembras, se reparten en igual número en tres edades: 11,12 y 13 años.
} 


$\begin{array}{lll}\text { Cuando } & 583 & 5,65 \% \\ \text { Como } & 453 & 4,39 \% \\ \text { Interrogativos } & 317 & 3,08 \% \\ \text { Para que } & 150 & 1,45 \% \\ \text { Donde } & 134 & 1,30 \% \\ \text { Hasta que - Desde que } & 70 & 0,67 \% \\ \text { Como si/Por si } & 63 & 0,61 \% \\ \text { Otros } & 55 & 0,53 \% \\ \text { Antes/después de que/inf } & 46 & 0,44 \% \\ \text { Aunque } & 31 & 0,30 \% \\ \text { Mientras - Mientras que } & 31 & 0,30 \% \\ \text { Total: } & \mathbf{1 0 . 3 2 5} & \mathbf{1 0 0 \%}\end{array}$

Son, como puede verse, los relativos y la conjunción que los nexos subordinantes más utilizados, sumando entre ambos aproximadamente el $57 \%$ del total. Por contra, aquellos subordinantes que presentan un menor rendimiento son, en orden decreciente, hasta que/desde que, como si-por si, otros, antes/después de que/inf., aunque y mientras-mientras que, cuyos índices porcentuales no alcanzan, en cada caso, el 1 por ciento. En cuanto a los demás, y dejando aparte la conjunción porque con el 11,50\% de uso, hemos de señalar que muestran unos valores porcentuales que oscilan entre el 6,98\% (720 ocurrencias) de las construcciones preposición + infinitivo y el 1,30\% ( 134 ocurrencias) del relativo adverbial donde. Completemos ahora nuestro comentario sociolingüístico conforme a las variables antes mencionadas:

a) Según la variable de sexo:

$\begin{array}{lll} & \text { varones } & \text { hembras } \\ \text { Relativos } & 52,02 \% & 47,98 \% \\ \text { Que } & 49,57 \% & 50,43 \% \\ \text { Porque } & 49,52 \% & 50,46 \% \\ \text { Prep. + infinitivo } & 55,13 \% & 44,87 \% \\ \text { Si } & 46,90 \% & 53,10 \% \\ \text { Cuando } & 48,89 \% & 51,11 \% \\ \text { Como } & 43,71 \% & 56,29 \% \\ \text { Interrogativos } & 48,25 \% & 51,75 \% \\ \text { Para que } & 51,99 \% & 48,01 \% \\ \text { Donde } & 50,76 \% & 49,24 \% \\ \text { Hasta que }- \text { Desde que } & 52,85 \% & 47,15 \%\end{array}$




$\begin{array}{lll}\text { Como si - Por si } & 65,09 \% & 34,91 \% \\ \text { Otros } & 62,06 \% & 37,94 \% \\ \text { Antes/después de que/inf } & 54,34 \% & 45,65 \% \\ \text { Aunque } & 64,50 \% & 35,50 \% \\ \text { Mientras - Mientras que } & 25,81 \% & 74,19 \%\end{array}$

Se aprecia, por un lado, la igualdad existente en los índices porcentuales correspondientes a la producción discursiva de los nexos que, porque y donde; y por otro, la significativa desproporción de los resultados aportados por los nexos como si-por si, prep. + infinitivo, otros, antes/después de que/inf., aunque y mientras-mientras que. Los varones emplean más los relativos $(52,02 \%)$, las construcciones de prep. + infinitivo $(55,13 \%)$, para que $(51,99 \%)$, donde $(50,76 \%)$, hasta que - desde que $(52,85 \%)$, como si - por si $(65,09 \%)$, otros $(62,06 \%)$, antes/después de que/inf. $(54,34 \%)$ y la conjunción aunque $(64,50 \%)$. Las hembras, por su parte, hacen lo propio con los nexos que $(50,43 \%)$, porque $(50,46 \%)$, si $(53,10 \%)$, cuando $(51,11 \%)$, como $(56,29 \%)$, interrogativos $(51,75 \%)$ y mientras - mientras que $(74,19 \%)$.

b) Según la variable de edad:

$\begin{array}{llll} & \text { 11 años } & \mathbf{1 2} \text { años } & \mathbf{1 3} \text { años } \\ \text { Relativos } & 31,69 \% & 31,80 \% & 36,51 \% \\ \text { Que } & 29,68 \% & 34,64 \% & 35,68 \% \\ \text { Porque } & 30,04 \% & 28,94 \% & 41,02 \% \\ \text { Prep. + infinitivo } & 33,88 \% & 30,56 \% & 35,56 \% \\ \text { Si } & 37,25 \% & 28,68 \% & 34,07 \% \\ \text { Cuando } & 30,02 \% & 32,58 \% & 37,40 \% \\ \text { Como } & 28,03 \% & 33,56 \% & 38,41 \% \\ \text { Interrogativos } & 33,76 \% & 35,95 \% & 30,29 \% \\ \text { Para que } & 27,33 \% & 40,66 \% & 32,01 \% \\ \text { Donde } & 21,64 \% & 39,54 \% & 38,82 \% \\ \text { Hasta que - Desde que } & 30,00 \% & 35,71 \% & 34,28 \% \\ \text { Como si }- \text { Por si } & 30,15 \% & 33,33 \% & 36,50 \% \\ \text { Otros } & 31,03 \% & 22,41 \% & 46,56 \% \\ \text { Antes/después de que/inf. } & 36,95 \% & 26,10 \% & 36,95 \% \\ \text { Aunque } & 12,90 \% & 35,50 \% & 51,60 \% \\ \text { Mientras-Mientras que } & 35,48 \% & 45,16 \% & 19,36 \%\end{array}$

En cuanto a la edad, se observa una progresión ascendente del porcentaje numérico en el uso de un grupo de elementos nexuales integrado por los relativos, la conjunción que, 
cuando, como, como si - por si y aunque. Con respecto a los demás: porque, la combinación prep. + infinitivo y otros aparecen mayoritariamente entre los niños de trece años; la conjunción si, por los más pequeños; las locuciones antes/después de que/inf., tanto por los de once como por los de trece años y los restantes, por los informantes de doce años.

CONJUNCIÓN QUE. Con el 25,23\% de uso ocupa la segunda posición, precedido tan sólo por los relativos. Consolidado su empleo desde edad muy temprana, se convierte en el nexo subordinante más productivo de nuestra lengua debido fundamentalmente a sus diversos valores plurifuncionales. Así pues, nada de extraño tiene que entre nuestro grupo de hablantes sea el transpositor más importante tanto por su frecuencia de uso como por el gran número de relaciones sintácticas que llega a establecer. El número de ocurrencias documentadas (2.604 casos) confirma realmente su alto rendimiento sociolingüístico. Estas, a su vez, pueden repartirse de la siguiente forma:

$\begin{array}{lll}\text { Sustantivador } & 2.338 & 89,78 \% \\ \text { comparativo }^{2}: & 147 & 5,65 \% \\ \text { causal: } & 96 & 3,68 \% \\ \text { consecutivo }^{3}: & 20 & 0,76 \% \\ \text { final: } & 3 & 0,11 \%\end{array}$

Según se desprende de estos datos, el nexo que sustantivador nos ofrece el mayor rendimiento discursivo gracias a su cometido en la transposición de una oración a nombre. El resto, tal como era de esperar, se sitúa a una considerable distancia con respecto a los índices de frecuencia mostrados por el primero y conjuntamente abarca casi el $10 \%$. Si tenemos ahora en cuenta la variable de edad, obtendremos estos otros resultados:

\footnotetext{
${ }^{2} \mathrm{El}$ análisis de las oraciones comparativas sigue siendo un punto muy discutido entre los gramáticos. Una de las cuestiones problemáticas gira en torno a la funcionalidad del relacionante que. Para E. Alarcos Llorach, en Estudios de gramática funcional del español (MADRID 1980) 274, este que (que3 según su terminología) es una conjunción que une segmentos equifuncionales de cuantificación diferente. Otros autores prefieren asimilarlo al que relativo (J.A. MARTÍNEZ GARCÍA, "Oraciones consecutivas y comparativas", en Lecciones del I y II Curso de Lingüistica Funcional,1983-84, 119) o bien lo diferencian del que anunciativo y del que relativo con la denominación de que valorativo (J. AlCINA, y J.M. BLECUA, Gramática española, Barcelona, 1983, 1042). A. ÁLVAREZ MENÉNDEZ, en Las construcciones consecutivas en español (OVIEDO 1989) 118-119, habla de un que-2 con un valor abstracto en el que se incluyen, además de los valores relativo y consecutivo, el comparativo. S. GUTIÉRREZ ORDÓÑEZ, en Estructuras comparativas (MADRID 1997) 36, le otorga una naturaleza distinta a la del quel y que2: se trata de un que3, no coordinante, "transpositor de un segmento de diiscurso (oracional o no) que pasa a funcionar como término adyacente de un adverbio o adjetivo de intensidad aunque sin funcionar como coordinante".

${ }^{3}$ También este tipo de construcciones presenta problemas de ubicación. Tradicionalmente, aparecen incluidas entre las subordinadas adverbiales, si bien no faltan voces que discrepen de tal clasificación. Según la Academia, en Esbozo de una Nueva Gramática de la Lengua Española (MADRID 1978) 553, "la consecuencia de una acción, circunstancia o cualidad indicada en la oración principal, a la que se unen por medio de la conjunción que, la cual se refiere a los antecedentes tanto, tan, de modo, de manera, así, generalmente expresos en la principal". Para E. Alarcos Llorach, en Gramática de la Lengua Española (MADRID 1995) 348, son oraciones transpuestas que han de examinarse con las de relativo. El antecedente sería, en cualquier caso, el elemento cuantificador.
} 


$\begin{array}{llll} & \mathbf{1 1} & \mathbf{1 2} & \mathbf{1 3} \\ \text { sustantivador } & 703 & 824 & 811 \\ \text { comparativo } & 37 & 38 & 72 \\ \text { causal } & 29 & 31 & 36 \\ \text { consecutivo } & 1 & 9 & 9 \\ \text { final } & 3 & - & -\end{array}$

CUADRO I: Que (conjunción)

$\begin{array}{lllll} & \text { 11 años } & \text { 12 años } & \text { 13 años } & \text { Totales } \\ \text { V } & 409(15,70 \%) & 448(17,20 \%) & 434(16,67 \%) & 1291(49,57 \%) \\ \text { H } & 364(13,97 \%) & 454(17,43 \%) & 495(19,00 \%) & 1313(50,43 \%) \\ \text { T } & 773(29,68 \%) & 902(34,64 \%) & 929(35,68 \%) & 2604(100 \%)\end{array}$

Se aprecia una mayor frecuencia de esta conjunción por parte de las niñas de mayor edad, con 495 ocurrencias, seguidas de las niñas y niños de 12 años, con 454 y 448 ocurrencias, respectivamente. Observamos igualmente un uso ascendente en el caso de las niñas pues conforme se avanza en edad, va incrementándose la utilización de este nexo. Entre los niños, esta tendencia se quiebra con un descendimiento del valor porcentual presentado por los mayores, con 434 ocurrencias. Por sexo, destaca la igualdad porcentual entre los informantes de 12 años.

RELATIVOS. Aparecen en la primera posición de entre los nexos registrados. Bajo esta denominación hemos incluido los siguientes elementos pronominales:

$\begin{array}{ll}\text { que: } & 2.509(77,22 \%) \\ \text { el que: } & 717(22,06 \%) \\ \text { quien: } & 22(0,67 \%) \\ \text { el cual: } & 1(0,03 \%)\end{array}$

De esta relación porcentual correspondiente al número de ocurrencias, destaca un fenómeno nada raro en la lengua hablada: nos referimos al uso hegemónico del que relativo, hecho que lo convierte en el transpositor por antonomasia dentro de las oraciones subordinadas adjetivas. Los otros nexos se mantienen ya a una considerable distancia: el pronombre quien, utilizado exclusivamente como relativo de sustantivación ${ }^{4}$ y el cual nos ofrecen

\footnotetext{
${ }^{4}$ Este uso de que con artículo que encabeza oraciones adjetivas sustantivadas no ha de ser confundido con el relativo compuesto el que, registrado en el apartado anterior. En este caso el artículo acompaña exclusivamente al pronombre que, mientras que el que describimos aquí afecta a toda la oración de la que forma parte. Además a diferencia de el que compuesto, el de sustantivación aparece siempre sin antecedente, excepto en los casos de las construcciones apositivas. A propósito del papel funcional del artículo en su relación con el pronombre relativo surgen opiniones opuestas. Dentro de nuestra tradición gramatical, se encuentra ampliamente difundida la teoría de que se trata de un artículo que conservaría su antiguo valor demostrativo. A través de esta equivalencia, el artículo es interpretado como verdadero antecedente del relativo, lo cual significa negarle su función sustantivadora. Esta
} 
una escasa presencia o, si se prefiere, testimonial en el caso de el cual. Mención aparte merece el que de sustantivación con una frecuencia total de 717 ocurrencias $(22,06 \%)$. Veamos en conjunto los resultados obtenidos:

CUADRO II: Relativos

$\begin{array}{lllll} & \text { 11 años } & \text { 12 años } & \text { 13 años } & \text { Totales } \\ \text { V } & 508(15,63 \%) & 540(16,63 \%) & 642(19,76 \%) & 1690(52,02 \%) \\ \text { H } & 522(16,06 \%) & 493(15,17 \%) & 544(16,75 \%) & 1559(47,98 \%) \\ \text { T } & 1030(31,69 \%) & 1033(31,80 \%) & 1186(36,51 \%) & 3249(100 \%)\end{array}$

En cuanto a su uso sociolingüístico, tenemos que decir que está ampliamente extendido en todas las edades y sexos. Asimismo, a diferencia de lo que sucede con las niñas, hemos de indicar la trayectoria porcentual ascendente que presentan los varones: según se avanza en la edad, aumenta el índice de empleo, significativo sobre todo a los trece años (642 casos). Por sexo, los niños adelantan a las niñas a los doce y trece años de edad, mientras que estas los aventajan a los once años. Entre los mayores es donde encontramos la desproporción porcentual más acusada.

INTERROGATIVOS. Tanto los pronombres interrogativos como los adverbios interrogativos introducen un tipo de subordinadas denominadas tradicionalmente interrogativas indirectas. Recordemos que en estas oraciones, en las que se realiza un pregunta aunque no formulada directamente, desaparecen tanto la entonación interrogativa como los propios signos de interrogación, características propias de las interrogativas directas. Solamente se conserva el carácter tónico de los nexos interrogativos, que desempeñan alguna función dentro de la subordinada. Agrupamos en estas dos columnas los casos recopilados a partir de nuestros textos orales:

$\begin{array}{ll}\text { Pronombres interrogativos } \\ \text { qué: } & 87(27,45 \%) \\ \text { quién: } & 27(8,51 \%) \\ \text { cuál: } & 8(2,52 \%)\end{array}$
Adverbios interrogativos
cómo: $106(33,43 \%)$
dónde: $76(23,98 \%)$
cuándo: $6(1,90 \%)$
cuánto: $7(2,20 \%)$

Se distinguen según la edad y el sexo en las siguientes proporciones:

postura apoyada por importantes gramáticos, con A. Bello a la cabeza, se opone abiertamente a la representada por Alarcos Llorach, Hernández Alonso, Gili Gaya y Marcos Marín, entre otros, quienes defienden la existencia de la sustantivación mediante el artículo. 
CUADRO III: Interrogativos

$\begin{array}{lllll} & \text { 11 años } & \text { 12 años } & \text { 13 años } & \text { Totales } \\ \text { V } & 59(18,61 \%) & 49(15,45 \%) & 45(14,19 \%) & 153(48,25 \%) \\ \text { H } & 48(15,15 \%) & 65(20,50 \%) & 51(16,10 \%) & 164(51,75 \%) \\ \text { T } & 107(33,76 \%) & 114(35,95 \%) & 96(30,29 \%) & 317(100 \%)\end{array}$

Los máximos porcentajes de uso se dan entre las niñas de doce años $(20,50 \%)$, seguidas de cerca por los niños de once $(18,61 \%)$. Por sexo, son las niñas de doce y trece años de edad quienes se destacan en el empleo de estos interrogativos. Digamos, por otra parte, que entre los varones se va produciendo un curioso descendimiento gradual en la proporción estadística conforme aumenta su edad.

DONDE. Las relaciones oracionales de lugar se observan a través del adverbio relativo donde. Presentamos las cifras porcentuales en este cuadro:

\section{CUADRO IV: Donde}

$\begin{array}{lllll} & \mathbf{1 1} \text { años } & \mathbf{1 2} \text { años } & \mathbf{1 3} \text { años } & \text { Totales } \\ \text { V } & 15(11,20 \%) & 28(20,90 \%) & 25(18,66 \%) & 68(50,76 \%) \\ \text { H } & 14(10,44 \%) & 25(18,64 \%) & 27(20,16 \%) & 66(49,24 \%) \\ \text { T } & 29(21,64 \%) & 53(39,54 \%) & 52(38,82 \%) & 134(100 \%)\end{array}$

Partimos de la escasa diferencia de empleo de esta forma por parte de ambos sexos, fundamentalmente en los niños y niñas de once años con el $11,20 \%$ y $10,44 \%$, respectivamente. Las diferencias se acentúan algo más cuando hacemos intervenir la variable de edad. En este sentido hemos de destacar la progresión ascendente del uso de este adverbio relativo entre las niñas $(10,44 \%, 18,64 \%$ y $20,16 \%)$. En los varones, por su parte, el mayor porcentaje numérico corresponde a los de doce años, mientras que el menor tiene lugar en los más pequeños.

CUANDO. Este adverbio relativo, de significado léxico de tiempo, puede referirse a un antecedente al que especifica, aunque lo normal es que se prescinda de él. Su distribución por grupos sociolingüísticos, según las variables con que venimos trabajando queda así:

\section{CUADRO V: Cuando}

$\begin{array}{lllll} & \text { 11 años } & \text { 12 años } & \text { 13 años } & \text { Totales } \\ \text { V } & 81(13,90 \%) & 95(16,29 \%) & 109(18,70 \%) & 285(48,89 \%) \\ \text { H } & 94(16,12 \%) & 95(16,29 \%) & 109(18,70 \%) & 298(51,11 \%) \\ \text { T } & 175(30,02 \%) & 190(32,58 \%) & 218(38,82 \%) & 583(100 \%)\end{array}$

Observamos una progresión ascendente en el empleo de cuando según la edad de nuestros informantes, dándose la cifra más baja entre los sujetos de once años. Esta misma tendencia se detecta tanto en uno como en otro sexo. Como dato curioso, se produce la iguala- 
ción en el número de ocurrencias de ellos y ellas a los doce y trece años, eliminándose de esta forma cualquier posibilidad de intervención significativa de la variable de sexo. Todo lo contrario sucede entre los escolares de menor edad: aquí el índice más elevado pertenece a las hembras con el 16,12 por ciento, frente al 13,90 por ciento de los varones.

COMO. Este nexo es también uno de los más productivos del español actual por la pluralidad de los valores relacionantes que posee 5 . Para dar una idea más adecuada de cómo se reparte cuantitativamente su empleo, presentamos la siguiente distribución:

$\begin{array}{ll}\text { causal: } & 387(85,43 \%) \\ \text { modal: } & 35(7,72 \%) \\ \text { condicional: } & 24(5,29 \%) \\ \text { comparativo: } & 7(1,54 \%)\end{array}$

Sin lugar a dudas, se hace evidente la notable diferencia en cuanto al porcentaje numérico del valor modal frente a todos los demás. Claro predominio, por tanto, del como causal con el $85,43 \%$ y escaso rendimiento discursivo del resto de los valores funcionales.

\section{CUADRO VI: COmo}

$\begin{array}{lllll} & \mathbf{1 1} \text { años } & \mathbf{1 2} \text { años } & \mathbf{1 3} \text { años } & \text { Totales } \\ \text { V } & 49(10,81 \%) & 67(14,80 \%) & 82(18,10 \%) & 198(43,71 \%) \\ \text { H } & 78(17,22 \%) & 85(18,76 \%) & 92(20,31 \%) & 255(56,29 \%) \\ \text { T } & 127(28,03 \%) & 152(33,56 \%) & 174(38,41 \%) & 453(100 \%)\end{array}$

De las 453 ocurrencias que constituye el número total del nexo como, 127 corresponden a la primera edad, 152 a la segunda y 174 a la tercera, siendo el sexo femenino quien hace más uso con el 56,29\%. Esta ventaja no sólo se refleja en los resultados finales, sino también en cada una de las distintas edades estudiadas. Por sexo, la distancia más importante se produce en los informantes de once años. Las diferencias en el uso de este elemento relacionante entre las niñas de una y otra edad no es tan significativa como entre los niños. En los varones y hembras va en progresión de menos a más: más en los mayores. Los informantes que más lo usan, con 92 ocurrencias, son las niñas de trece años.

PARA QUE. Por medio de las construcciones sintácticas que encabeza este nexo conjuntivo ${ }^{6}$ se puede expresar lingüísticamente la noción de finalidad en español. Su producción discursiva se reparte sociolingüísticamente de esta manera:

\footnotetext{
${ }^{5}$ Para un estudio más detallado del como en español: A. MORENO AYORA, Sintaxis y semántica de como (MÁLAGA 1991).

${ }^{6}$ Para Alarcos y otros autores, recordemos, esta conjunción ha de interpretarse como la fusión de dos elementos funcionales: la preposición para indica la finalidad y el transpositor conjuntivo que, por esta razón, y con palabras de Hernández Alonso, "la pretendida gramaticalización y lexicalización del grupo no se da" (Gramática funcional del español, Madrid, 1986, 237).
} 
CUADRO VII: Para que

$\begin{array}{lllll} & \text { 11 años } & \text { 12 años } & \text { 13 años } & \text { Totales } \\ \text { V } & 20(13,33 \%) & 29(19,33 \%) & 29(19,33 \%) & 78(51,99 \%) \\ \text { H } & 21(14,00 \%) & 32(21,33 \%) & 19(12,68 \%) & 72(48,01 \%) \\ \text { T } & 41(27,33 \%) & 61(40,66 \%) & 48(32,01 \%) & 150(100 \%)\end{array}$

Se comprueba un mayor empleo en las niñas de doce años, con 61 casos $(40.66 \%)$. Analizando pormenorizadamente nuestras variables sociológicas, constatamos predominio en las hembras a los doce años y en los varones a los trece, si bien a los doce años la diferencia es mínima, mientras que a los trece la distancia entre ambos sexos aumenta sensiblemente; en los informantes de menor edad el sexo no representa ninguna relevancia $(13,33 \%$ en ellos y $14,00 \%$ en ellas). Por otro lado, según la edad reseñamos la igualdad porcentual que presentan los niños de doce y trece años y el significativo descenso del número de ocurrencias que se da en las niñas de doce en años con respecto de las mayores.

PORQUE. De entre los variados recursos lingüísticos que permiten expresar la causa tenemos las oraciones subordinadas causales introducidas por el nexo porque. Las 1.180 apariciones recogidas se reparten del siguiente modo:

CUADRO VIII: Porque

$\begin{array}{lllll} & \mathbf{1 1} \text { años } & \text { 12 años } & \text { 13 años } & \text { Totales } \\ \text { V } & 178(14,98 \%) & 160(13,46 \%) & 250(21,08 \%) & 588(49,52 \%) \\ \text { H } & 179(15,06 \%) & 184(15,48 \%) & 237(19,94 \%) & 600(50,46 \%) \\ \text { T } & 357(30,04 \%) & 344(28,94 \%) & 487(41,02 \%) & 1188(100 \%)\end{array}$

Partiendo de las cifras porcentuales de este cuadro, nos damos cuenta de que existe una notable diferencia en lo que se refiere al porcentaje numérico en la variable edad, ya que va desde un 28,94 a los doce años, un $30,04 \%$ a los once, hasta un 41,02 a los trece, siendo los niños y niñas de esta edad quienes aportan el índice de aceptabilidad más alto.

Con respecto a la variable sexo, el índice más elevado de aceptabilidad corresponde a los niños de trece años con un $21,08 \%$, seguido de las niñas de esta misma edad con un $19,94 \%$ y, por último, del resto de informantes que se aproximan en el porcentaje numérico, situándose entre el $13,46 \%$ de las niñas de doce años y el 15,48 de los niños de la misma edad. Hemos de indicar igualmente que esta variable no es pertinente en los más pequeños puesto que se da un porcentaje similar en los dos sexos, resaltando ligeramente el empleo que de él realizan las hembras. La edad es claramente determinante en las hembras dado que el índice de uso es mayor cuanto mayor es la edad de ellos, dándose la cifra más baja a los once años. En el caso de los varones, se produce un ligero descenso porcentual a los doce años. Partimos, pues, de la escasa diferencia de empleo de porque por parte los dos sexos. Pero, a pesar de ello, el mayor porcentaje de ocurrencias tiende a sobresalir entre ellas. 
SI. En el significante si coinciden dos unidades átonas y dependientes: una sirve para transponer una oración interrogativa a funciones propias del sustantivo y la otra es la conjunción llamada condicional. Los 631 ocurrencias registradas, 522 usos corresponden al, si condicional, frente a 109 del de sustantivación:

$$
\begin{array}{ll}
\text { si condicional: } & 522(82,72 \%) \\
\text { si de sustantivación: } & 109(17,28 \%)
\end{array}
$$

Estas ocurrencias se distribuyen según la edad y el sexo en las siguientes proporciones:

CUADRO IX: $S i$

$\begin{array}{lllll} & \text { 11 años } & \text { 12 años } & \text { 13 años } & \text { Totales } \\ \text { V } & 96(15,21 \%) & 88(13,94 \%) & 112(17,75 \%) & 296(46,90 \%) \\ \text { H } & 139(22,04 \%) & 93(14,74 \%) & 103(16,32 \%) & 335(53,10 \%) \\ \text { T } & 235(37,25 \%) & 181(28,68 \%) & 215(34,07 \%) & 631(100 \%)\end{array}$

Interpretando estos datos, observamos una sensible presencia de si por parte de las hembras, con el 53,10 por ciento, correspondiendo el índice de frecuencia parcial más alto a las niñas de menor edad $(22,04 \%)$, seguido de los niños de trece años $(17,75 \%)$. Destaca que sea en los más jóvenes donde se produzca un mayor distanciamiento porcentual en razón del sexo, lo cual contribuye a ese predominio de las hembras sobre los varones en los resultados globales.

PREPOSICIÓN + INFINITIVO. En otras clases de relaciones oracionales, como es bien sabido, los nexos que actúan como subordinantes son las preposiciones; así sucede en el caso de las oraciones de infinitivo. Recuérdese que estas oraciones ya se encuentran nominalizadas por la propia forma del infinitivo, por ello si precisan "un nexo subordinante para incidir sobre una categoría primaria, dicho nexo adquiere siempre la forma de una preposición y no la de conjunción"7. Veamos cuáles son estas preposiciones:

$$
\begin{array}{ll}
\text { a+Vinf.: } & 358(49,72 \%) \\
\text { para+Vinf.: } & 329(45,69 \%) \\
\text { al+Vinf.: } & 42(5,83 \%) \\
\text { sin+Vinf.: } & 20(2,77 \%) \\
\text { por+Vinf.: } & 8(0,83 \%)
\end{array}
$$

CUADRO X: Prep. + infinitivo

$$
\begin{array}{lllll} 
& \text { 11 años } & \text { 12 años } & \text { 13 años } & \text { Totales } \\
\text { V } & 137(19,02 \%) & 111(15,41 \%) & 149(20,70 \%) & 397(55,13 \%) \\
\text { H } & 107(14,86 \%) & 109(15,15 \%) & 107(14,86 \%) & 323(44,87 \%) \\
\text { T } & 244(33,88 \%) & 220(30,56 \%) & 256(35,56 \%) & 720(100 \%)
\end{array}
$$

${ }^{7}$ P. CARBONERO CANO, Funcionamiento lingüístico de los elementos de relación (SEVILLA 1975) 87. 
Apreciamos que entre las niñas encontramos una casi igualdad en el tanto por ciento de los usos a lo largo de las tres edades analizadas. En los hombres se distinguen los de trece años y los de once años, pero sobre todo los primeros, con un número de ocurrencias que alcanza el $20,70 \%$. Son los que han obtenido mayor producción, en tanto que los demás grupos mantienen unos porcentajes muy igualados, entre los que se destaca el resultado obtenido en las hembras, las cuales presentan los más bajos números de ocurrencias.

HASTA QUE/DESDE QUE. Ambas conjunciones coinciden en que expresan la delimitción del periodo temporal indicando su inicio y su finalización:

CUADRO XI: Hasta que/Desde que

$\begin{array}{lllll} & \text { 11 años } & \text { 12 años } & \text { 13 años } & \text { Totales } \\ \text { V } & 7(10,00 \%) & 15(21,42 \%) & 15(21,42 \%) & 37(52,85 \%) \\ \text { H } & 14(20,00 \%) & 10(14,29 \%) & 9(12,86 \%) & 33(47,15 \%) \\ \text { T } & 21(30,00 \%) & 25(35,71 \%) & 24(34,28 \%) & 70(100 \%)\end{array}$

Según se observa, en las hembras las frecuencias de uso van en descenso, siendo los niñas de trece años quienes menos empleo efectúan. Los varones de doce y trece años mantienen idéntico número de ocurrencias. En cuanto a las cifras globales percibimos nuevamente mayor uso de estas dos locuciones en los niños.

COMO SI/POR SI. Estas dos locuciones conjuntivas coinciden en que sus respectivos significados -modal y causal- se encuentran matizados por el valor condicional de $s i$.

CUADRO XII: Como si/por si

$\begin{array}{lllll} & \text { 11 años } & \text { 12 años } & \text { 13 años } & \text { Totales } \\ \text { V } & 11(17,46 \%) & 14(22,22 \%) & 16(25,41 \%) & 41(65,09 \%) \\ \text { H } & 8(12,69 \%) & 7(11,11 \%) & 7(11,11 \%) & 22(34,91 \%) \\ \text { T } & 19(30,15 \%) & 21(33,33 \%) & 23(36,50 \%) & 63(100 \%)\end{array}$

Interpretando estos valores, vemos la escasa o nula diferencia del porcentaje numérico existente entre las niñas de las tres edades contempladas, pues va desde un $12,69 \%$ en la edad de once años al $11,11 \%$ del resto de niñas. La progresión ascendente producida en los índices de aceptabilidad globales $(30,15 \%, 33,33 \%$ y $36,50 \%)$ se corrobora únicamente entre el sexo masculino, cosa que contrasta ciertamente con la coincidencia porcentual aportada por las hembras $(12,69 \%, 11,11 \%$ y $11,11 \%)$. En cuanto a la variable sexo, según los datos que ofrecemos, son los niños de trece años quienes presentan un tanto por ciento más elevado que los demás miembros del grupo sociolingüístico. Hay que señalar también la gran diferencia de uso entre hombres y mujeres a favor de aquellos. Se da más uso en los niños de trece años; y en las hembras existe casi una igualdad.

AUNQUE. Aparece el empleo de este nexo en nuestro corpus en 31 ocasiones. Teniendo en cuenta las variables de sexo y edad obtenemos estos resultados: 
CUADRO XIII: Aunque

$\begin{array}{lllll} & \text { 11 años } & \text { 12 años } & \text { 13 años } & \text { Totales } \\ \text { V } & 2(6,45 \%) & 8(25,80 \%) & 10(32,26 \%) & 20(64,51 \%) \\ \text { H } & 2(6,45 \%) & 3(9,68 \%) & 6(19,35 \%) & 11(35,48 \%) \\ \text { T } & 4(12,90 \%) & 11(35,48 \%) & 16(51,61 \%) & 31(100 \%)\end{array}$

La tendencia ascendente del uso de aunque que se deduce de los porcentajes globales, se produce igualmente entre los varones y las hembras. Ambos sexos parten del mismo índice porcentual a los once años $(6,45 \%)$. A partir de ahí el predominio va a corresponder a los niños de doce y trece años con el $25,80 \%$ y $32,26 \%$, respectivamente. La diferencia más alta se produce, sin duda alguna, entre los niños de once y doce años.

MIENTRAS/MIENTRAS QUE. La agrupación del uso de cada uno de estos nexos con un total de 31 ocurrencias representa tan sólo el 0,30 por ciento de entre los elementos relacionantes empleados discursivamente por nuestros hablantes. Este exiguo número de apariciones se reparte por sexo y edad de esta forma:

CUADRO XIV: Mientras/Mientras que

$\begin{array}{lllll} & \text { 11 años } & \text { 12 años } & \text { 13 años } & \text { Totales } \\ \text { V } & 2(6,45 \%) & 3(9,68 \%) & 3(9,67 \%) & 8(25,80 \%) \\ \text { H } & 9(29,03 \%) & 11(35,48 \%) & 3(9,67 \%) & 23(74,19 \%) \\ \text { T } & 11(35,48 \%) & 14(45,16 \%) & 6(19,34 \%) & 31(100 \%)\end{array}$

Sobre el rendimiento de las variables sociolingüísticas: sensible aumento del uso en las niñas de once y doce años frente a la coincidencia en el porcentaje numérico del resto de informantes. Como puede comprobarse, los varones, además de presentar un escaso empleo de estos elementos nexuales, no ofrecen apenas diferencia alguna en los valores porcentuales pertenecientes a cada una de las edades estudiadas.

ANTES/DESPUÉS DE QUE/INF. Este tipo de construcciones nos da una frecuencia total de 46 ocurrencias $(0,44 \%)$. Su distribución por grupos sociolingüísticos, según las variables de sexo y edad queda expuesta en el siguiente cuadro:

CUADRO XV: Antes/después de que/inj.

$\begin{array}{lllll} & \text { 11 años } & \text { 12 años } & \text { 13 años } & \text { Totales } \\ \text { V } & 8(17,39 \%) & 6(13,04 \%) & 11(23,91 \%) & 25(54,34 \%) \\ \text { H } & 9(19,56 \%) & 6(13,04 \%) & 6(13,04 \%) & 21(45,65 \%) \\ \text { T } & 17(36,95 \%) & 12(26,08 \%) & 17(36,95 \%) & 46(100 \%)\end{array}$

Como se deduce de estos porcentajes, en el caso de los varones está claro que a mayor edad, más uso (23,91\%); no sucede lo mismo, sin embargo, si nos centramos en las niñas pues en este grupo se marca la tendencia opuesta, esto es, son los hablantes de menor edad 
quienes superan a los demás. Hagamos notar también que la igualdad en las cifras porcentuales entre los niños y niñas de once y doce años. El sexo sí parece ser más significativo entre los mayores por el predominio de los varones: $11(23,91 \%)$ frente a $6(13,04 \%)$ en las hembras.

OTROS NEXOS. Agrupamos en este último subapartado otros nexos relacionantes del discurso, locuciones conjuntivas ${ }^{8}$ en su gran mayoría, que nos ofrecen unos índices de uso bastante inferiores a los hasta ahora descritos. Fundamentalmente son formaciones conjuntivas en las que diacrónicamente se han ido integrando diversos componentes de variada naturaleza gramatical. Ahora bien, desde una perspectiva de sincronía actual hemos de considerarlas como una sola unidad funcional, es decir, con un comportamiento sintáctico unitario: cada vez que: 16 casos, sin que: 8 casos, ya que: 7 casos, a que: 7 casos, a no ser que: 6 casos, siempre que: 5 casos, una vez que: 3 casos, por mucho que: 3 casos:

CUADRO XVI: Otros nexos

$\begin{array}{lllll} & \text { 11 años } & \text { 12 años } & \text { 13 años } & \text { Totales } \\ \text { V } & 14(25,45 \%) & 4(7,27 \%) & 17(19,76 \%) & 35(63,63 \%) \\ \text { H } & 4(7,27 \%) & 8(14,54 \%) & 8(14,54 \%) & 20(36,37 \%) \\ \text { T } & 18(32,72 \%) & 12(21,81 \%) & 25(45,46 \%) & 55(100 \%)\end{array}$

Atendiendo a los resultados globales, comprobamos una mayor frecuencia de uso entre los varones con el $63,63 \%$. En la variable sexual se produce un descendimiento porcentual a la edad de doce años provocado por el escaso índice de empleo registrado entre los niños de doce años. Frente al 25,45 por ciento de los de menor edad y el 19,76 de los mayores, aquellos no superan el $8 \%$. Entre las niñas, sin embargo, a pesar de arrojar menor número de ocurrencias, apreciamos que las cifras más elevadas se corresponden con los grupos de más edad.

\section{FINAL}

La cuantificación y el contraste sociolingüístico nos ha permitido describir la actualización de los nexos subordinantes que realiza un grupo de niños sevillanos en el discurso oral. A pesar de que gran parte de las variables lingüísticas sólo nos haya presentado tendencias generales, lo cierto es que los resultados obtenidos han contribuido significativamente al conocimiento de la sintaxis de la lengua hablada de los niños. Ese ha sido nuestro objetivo: diagnosticar el saber idiomático de unos hablantes muy determinados en diversas etapas de su aprendizaje lingüístico.

\footnotetext{
${ }^{8}$ Según Hernández Alonso (1986: 124) "la tradición había formado uniđades léxicas (locuciones conjuntivas como luego que, así que, antes que, ya que ...) y les había asignado la función de unión de las proposiciones que encabezaban. Mas desde un punto de vista lingǘstico, y estrictamente funcional, esto es improcedente, pues tales grupos constan de dos unidades funcionales: por un lado el adverbio, núcleo del sintagma, y por otro el nexus introducido por que". Véase también E. MÉNDEZ GARCÍA DE PAREDES, "Naturaleza gramatical de que en algunas locuciones conjuntivas", Actas del Congreso de la Sociedad Española de Lingüística Española. XX aniversario, t. II, (1991) 668-680.
} 